per thousand and in the vaccinated children 2.2 per thousand. The probability of this difference arising by chance is less than one in a million. Thus under the conditions of this trial B.C.G. vaccination reduced the incidence of leprosy by $80 \%$.

This work shows beyond doubt the benefit of B.C.G. vaccine in preventing the development of leprosy in young children with negative or weak tuberculin reactions who are at special risk by being exposed to relatives or contacts with leprosy of lepromatous or tuberculoid type. The most surprising finding was that B.C.G. vaccination gave much the same protection ( $80 \%$ ) against leprosy as was obtained by the Medical Research Council in their trials against tuberculosis. $^{2}$ However, these results are consistent with the recent observations that B.C.G. vaccination diminishes the multiplication of $M$. leprae in experimental leprosy in the mouse foot-pad. ${ }^{3}$ Very wisely, Kinnear Brown and Stone are cautious in suggesting that their preliminary results will be as significant after a longer follow-up. The reason for their caution is that leprosy is a slowly developing chronic disease of variable course, and spontaneous healing occurs in some children with early tuberculoid-type lesions. This latter point is emphasized because all the cases of leprosy found so far in the follow-up period were of the early tuberculoid type. Furthermore, follow-up at one to three years of the children with leprosy detected at intake showed that in $8 \%$ the disease had resolved completely and in a further $21 \%$ it appeared to be resolving at the time. Only continuing regular follow-up will determine whether B.C.G. vaccination protects against fully developed tuberculoid leprosy, which if left untreated may lead to severe nerve damage. In Uganda, as in most of Africa, some $90 \%$ of leprosy is of the tuberculoid type. The more severe and highly infectious lepromatous type affects some $8 \%$ of patients in the Teso area, and in the first follow-up period no lepromatous cases were found in these children. Again, it is hoped that the trial will be continued in order to see whether B.C.G. vaccination protects also against leprosy of lepromatous type. In this respect the large-scale trial of this vaccine started recently by the World Health Organization ${ }^{4}$ in Burma will be of particular importance, because there the proportion of lepromatous disease is between 40 and $70 \%$.

Although it will be essential to continue the follow-up in this Uganda trial for at least a further five years, the prophylactic effect of B.C.G. already seen against the development of early cases of tuberculoid leprosy in children suggests that this measure should be incorporated now into programmes of leprosy control. Because the peak incidence of the disease is reached at the age of 15 years there is a good case for vaccinating within the first year of life and certainly all children up to the age of 15 years. The recent recommendation by the W.H.O. Expert Committee on Tuberculosis $^{5}$ that B.C.G. vaccination can be safely given without prior tuberculin testing indicates that it could be incorporated into schemes for the control of leprosy without employing specially trained staff. Finally, the results of the Uganda B.C.G. trial come soon after publication of some preliminary results from a continuing, long-term study in India, ${ }^{6}$ which shows that dapsone may have a prophylactic effect in persons exposed to leprosy. The two together may

- Fernandez, J. M. M., Rev. argent. Dermatosif., 1939, 23, 425.

- Medical Research Council, Brit. med. 7., 1956, 1, 413.

- Shepard, C. C., Amer. f. Epidem., 1965, 81, 150.

- World Health Örganization. Report MHO/PA/131.64. 1964. Geneva.

- World Wld Hlth Org. techn. Rep. Ser., 1964, 290.

- W. Amer. med. Ass., 1965, 192, Med. News p. 34. thus provide for the first time preventive measures which will help to eradicate once and for all this dreaded infection.

\section{Hypertrophic Obstructive Cardiomyopathy}

In 1957 Sir Russell (now Lord) Brock described "Functional obstruction of the left ventricle,"1 and D. Teare the following year described the morbid anatomy under the title "Asymmetrical hypertrophy of the heart."2 The condition has now become known in Great Britain as hypertrophic obstructive cardiomyopathy ${ }^{3}$ and in the United States as idiopathic hypertrophic subaortic stenosis. ${ }^{5}$ A recent Ciba Foundation Symposium $^{6}$ and American Heart Association Monograph ${ }^{7}$ show how surprisingly frequent this disorder is now that precise haemodynamic study and angiocardiography have stripped it of many of its disguises.

The main feature of it is a grotesquely hypertrophied cardiac muscle which contracts with unusual force but whose growth is unexplained by structural abnormality or hypertension. In this it differs from all other primary disorders of heart muscle. Obstruction to ventricular ejection seemingly results from over-exuberant myocardial activity, and impediment to ventricular filling follows from the relative indistensibility of the massively thickened ventricular walls. There results the great cardiac mimic, typically resembling organic aortic stenosis or mitral incompetence or both, but able to simulate mitral or tricuspid stenosis, ventricular or atrial septal defect, and, least often, other forms of cardiomyopathy.

The aetiology is unknown; a familial incidence is noted in about one-third of cases. The sexes are probably affected equally, but $\mathrm{E}$. Braunwald and colleagues ${ }^{7}$ found the familial form to be commoner in males. The condition has been described in the newborn baby, ${ }^{8}$ is seen in childhood, but most often presents in the third decade. Though usually progressive, arrest or even regression of the obstruction sometimes occurs.

Afflicted persons are often of athletic disposition and good physical development. Heart failure and atrial fibrillation are rare. The haemodynamic abnormality determines some characteristic physical signs. The left ventricle starts to empty abnormally fast but obstructs itself before completion of ejection by apposition of its hypertrophied walls. Dizzy spells, syncope, angina, and sudden death are distressingly frequent, though in contrast to organic aortic stenosis the arterial pulses are full and jerky. A murmur which is maximal at the lower left sternal edge but only poorly conducted to the base of the heart and carotid arteries is heard late in systole and coincides with the delayed onset of obstruction. Neither ejection clicks nor early diastolic murmurs are heard and calcium is not found in the aortic valve. Functional mitral incompetence also begins when the outflow becomes obstructed, and may contribute to the late systolic murmur, which then sometimes radiates to the axilla. Since the thick left ventricle requires an abnormally high venous filling pressure, the patient suffers severe dyspnoea, and the physician detects a forceful presystolic atrial beat giving a double impulse which seems excessive for the apparen severity of the " aortic stenosis."

In some cases obstruction in the left ventricle during systole is absent and obstruction during diastole dominates 
a picture which may now mimic neurosis, mitral stenosis, or or even disease of the lung. Rapidly completed left ventricular systole with early closure of the aortic valve may cause a widely split second sound whose pulmonary component is mistaken for the opening snap of mitral stenosis.

Massive septal hypertrophy may impede filling and ejection in both right and left ventricles. A giant venous " a " wave in the jugular venous pulse in the neck is sometimes noted and indicates that the atrium is contracting forcefully against an obstructed atrio-ventricular orifice. Though this sign may help in differentiation from aortic stenosis, either tricuspid or pulmonary stenosis may be diagnosed instead.

The heart is globular, with an aorta of normal size. Sometimes left atrial enlargement and evidence of pulmonary venous congestion suggest disease of the mitral valve. The electrocardiogram may show left ventricular or biventricular hypertrophy, and a pre-excitation pattern resembling the WolffParkinson-White syndrome is not uncommon. Both atria may be grossly hypertrophied, an appearance of help in diagnosis.

Catheterization localizes systolic gradients within the left ventricle or in both ventricles; ventricular diastolic and atrial pressures are high and show a prominent atrial "kick." Angiocardiography reveals distorted ventricular cavities which are abnormally small in systole and indented by the hypertrophied muscle masses. The left ventricle is characteristically elongated and bent like a banana by massive enlargement of the septum. Mild or moderate mitral incompetence is seen in over one-third of cases.

The problem of whether hypertrophy precedes obstruction or whether a disordered myocardial action causes the obstruction, with secondary hypertrophy, has been much debated. A. G. E. Pearse's discovery that the myopathic left ventricular muscle differs from the hypertrophied muscle of aortic stenosis in having shorter, wider myocardial fibres with some dystrophic features and stuffed with noradrenaline suggests that this may even be an endocrine disorder of the heart muscle. ${ }^{9}$ Characteristic of this disorder are the variability in the abnormal force of contraction, with consequent changing symptoms and signs, and rapid changes in the left ventricular peak of pressure. These led Braunwald first to investigate the effect of drugs on the abnormal haemodynamics.

Recently it has become apparent that a decrease in the volume of the left ventricle during systole may be the common factor determining an increase of obstruction with exercise, tachycardia, expiration, the strain period of the Valsalva manœuvre, peripheral vasodilatation by amyl nitrite during augmentation of the contractile force of the heart by drugs such as adrenaline and digitalis, and in the beat which follows a post-ectopic pause. These are patients who may really die of fright. Conversely left ventricular distension at the end of inspiration, during rapid venous infusion, or after a phenylephrine-induced rise in blood-pressure may diminish or

\footnotetext{
a Brock, R., Guy's Hosp. Rep., 1957, 106, 221.

2 Teare, D., Brit. Heart f., 1958, 20, 1.

Goodwin, J. F., Hollman, A., Cleland, W. P., and Teare, D., ibid., $1960,22,403$

4 Goodwin, J. F., Brit. med. F., 1964, 1, 1527 and 1595.

Braunwald, E., Morrow, A. G., Cornell, W. P., Aygen, M. M., and Hilbish, T. F., Amer. F. Med., 1960, 29, 924."

- Ciba Foundation Symposium on the Cardiomyopathies, ed. G. E. W. Wolstenholme and M. O'Connor. London. 1964.

- Braunwald, E., Lambrew, C. T., Rockoff, S. D., Ross, J., and Morrow, A. G., in American Heart Association, Monograph,

- Neufeld, H. N., Ongley, P. A., and Edwards, J. E., Brit. Heart f., 1960, 22, 686.

- Pearse, A. G. E., in Ciba Foundation Symposium on the Cardiomyopathies, ed. G. E. W. Wolstenholme and M. O'Connor. London.
1964.
}

abolish the obstruction. Indeed, all the evidence now suggests that the apparent "obstruction". is determined by continuing contraction of an empty ventricle after excessive and unduly rapidly completed ejection of its contents within the first few moments of systole.

Surgical excision of some of the hypertrophied muscle or a ventriculomyotomy along the lines of a Rammstedt operation for hypertrophic pyloric stenosis of infants may successfully relieve symptoms. The apparent success of widely differing surgical techniques suggests that perhaps the common denominator may be the production of relative heart failure with an increased leftventricular residual volume. The susceptibility of this abnormal myocardium to drugs has encouraged trial of medical means to alleviate the disorder. The use of betaadrenergic blockers, which prevent the cardiac actions of adrenaline, is logical but has had no dramatic results so far, and we still seem vainly to be groping for more effective medical therapy which may exist but which unfortunately eludes us.

\section{Alcohol and Driving}

Faced with the evidence that even fairly small amounts of alcohol impair human judgment and manipulative skill, the general public has come to acknowledge the need for considerable changes in the traditional patterns of social drinking. The confirmed alcoholic was recognized as a danger on the roads long before the motor-car replaced the horse. Now the public are learning to accept that the man who has a festive evening with friends can bring danger on to roads ever more densely crowded with fast vehicles. And many other countries have succeeded in introducing, and enforcing, laws to restrict drinking before driving. Consequently the main problems now confronting the Government have been to set a level of alcohol in the blood to which legal sanctions should be attached, and to devise an acceptable method for detecting it.

In taking a blood-alcohol of $80 \mathrm{mg}$. per $100 \mathrm{ml}$. as the level at which a driver is automatically to be subject to legal penalty the Government has acted in accordance with the advice of the B.M.A.'s Alcohol and Road Accidents Committee, which the Council endorsed last year. ${ }^{1}$ The Medical Research Council's views were also sought, and these are set out in the White Paper ${ }^{2}$ published last week: "They have concluded that the consumption of alcohol in amounts sufficient to cause a blood alcohol concentration of $50 \mathrm{mg}$./ $100 \mathrm{ml}$. or more would impair driving ability in an appreciable proportion of drivers, and that when the amount of alcohol consumed results in a concentration in the blood of $80 \mathrm{mg} . / 100 \mathrm{ml}$. or more, driving ability would be impaired in the great majority of drivers." But it is important to emphasize, as the White Paper points out, that alcohol in the blood at levels well below $80 \mathrm{mg}$. per $100 \mathrm{ml}$.- and even below the often quoted $50 \mathrm{mg}$. per $100 \mathrm{ml}$ - - can impair a driver's judgment. There is no "safe level." Consequently the present law is to remain unchanged by which prosecutions can be brought for driving under the influence of drink regardless of the amount actually taken. The effect of the new Act which the Government proposes to introduce is thus additional: to have a blood-alcohol level of at least $80 \mathrm{mg}$. per $100 \mathrm{ml}$. when driving will in itself make that person liable to a penalty. 